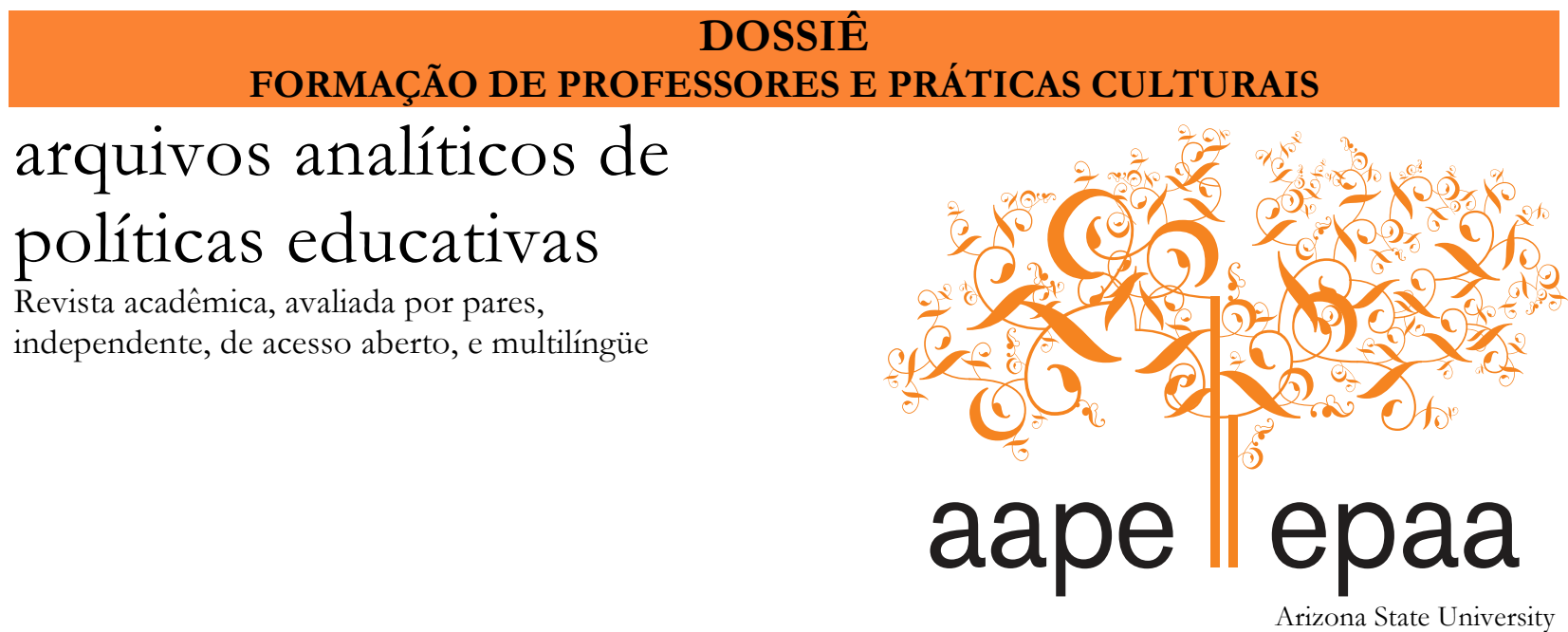

Arizona State University

Volume 21 Número $26 \quad 25$ de março $2013 \quad$ ISSN 1068-2341

\title{
Memórias traduzidas: docência compartilhada no processo de formação inicial de professores
}

\author{
Gilberto Ferreira da Silva \\ Maria Rosa Fontebasso \\ UNILASALLE \\ Brazil
}

Citação: Silva, G.F.; Fontebasso. M.R. (2012) Memórias traduzidas: docência compartilhada no processo de formação inicial de professores. Arquivos Analíticos de Políticas Educativas, Arquivos Analíticos de Politicas Educativas, 21(26). Dossiê Formação de professores e práticas culturais: descobertas, enlaces, experimentações. Editoras convidadas: Carla Beatriz Meinerz, Dóris Maria Luzzardi Fiss \& Sônia Mara Moreira Ogiba. Recuperado [data] http://epaa.asu.edu/ojs/article/view/1149

Resumo: Amparados pelo recurso da memória, os autores exploram analiticamente a experiência de docência compartilhada durante a realização de um curso de formação inicial de professores, reconstruindo desde contextos até fragmentos do que a memória seletiva permite reatualizar. São tecidas reflexões em que dimensões como o estranhamento, o poder, a insegurança e as crenças pessoais vão sendo aos poucos desvelados, trabalhados, dando lugar à parceria, cumplicidade e à reafirmação do compromisso com a educação. $\mathrm{O}$ trabalho evidencia as contribuições que o recurso da memória oferece aos processos reflexivos de se fazer educação, ainda que acionados tempos mais tarde. Demonstra, assim, uma alternativa a mais para desencadear processos analíticos sobre o que se faz em educação, principalmente no campo da formação de professores.

Palavras-chave: Memória; Formação inicial de professores; Docência compartilhada; Ensino superior.

Página web: http://epaa.asu.edu/ojs/

Artigo recebido: $28 / 06 / 2012$

Facebook: /EPAAA

Twitter: @epaa_aape

Revisões recebidas: 10/01/2013

Aceito: $13 / 02 / 2013$ 
Translated memories: Shared teaching in teacher training

Abstract: The authors explore analytically their memories of shared experience of teaching during the initial training class for beginner teachers. Contexts to recover from fragments of what selective memory allows revitalized. Reflections are woven into what dimensions as the strangeness, power, insecurity and personal beliefs are being gradually revealed, worked, giving way to partnership, complicity and reaffirmation of commitment to education. This work highlights the contributions that the use of memory offers reflective processes to make education but triggered later times. Thus discloses an alternative to more analytical processes to trigger on what we do in education, especially in the field of teacher education.

Keywords: Memory; Initial teacher education; Teaching shared; Higher education.

\section{Memorias traducidas: docencia compartida en el proceso de formación inicial de profesores.}

Resumen: Ayudados por el uso de la memoria, los autores exploran analíticamente la experiencia compartida de la enseñanza mientras la realización de un curso de formación inicial de profesores, recuperando contextos hasta fragmentos do que la memoria selectiva permite revitalizar. Son tejidas reflexiones en que dimensiones como el extrañamiento, el poder, la inseguridad y las creencias personales se revelan poco a poco una vez trabajados, dando lugar a la colaboración, a la complicidad y a la reafirmación del compromiso con la educación. Este trabajo pone de relieve las contribuciones que el uso de la memoria ofrece a los procesos reflexivos de hacer de la educación, aún que desencadenados tiempos más tarde. De este modo se demuestra otra alternativa para desencadenar procesos de análisis sobre el que hacer en educación, especialmente en el campo de la formación de profesores. Palabras-clave: Memoria; Formación inicial de profesores; Docencia compartida; Enseñanza superior.

\section{Introdução}

Alternativas em educação, principalmente na prática da Educação Básica ${ }^{1}$, têm sido um dos grandes vetores que mobilizam professores no cotidiano de seus espaços de atuação, sendo, com frequência, registradas e sistematizadas em trabalhos de conclusão de curso, dissertações de mestrado e teses de doutorado. Já no que se refere ao ensino superior, não podemos afirmar o mesmo, entretanto é possível apontar para o fato de que existem algumas experiências e projetos de formação de educadores que vão construindo outras formas de se pensar e fazer a formação inicial. Em uma dessas experiências, tivemos oportunidade de colaborar.

Idealizado pela Universidade Estadual do Rio Grande do Sul (UERGS), em parceria com a Prefeitura Municipal de Porto Alegre, o "Curso 150" tinha por objetivo formar educadores em serviço em meios populares no nível superior, em outras palavras, um curso de pedagogia, organizado por componentes curriculares, sendo que cada componente era ministrado por dois formadores, as aulas do curso aconteciam aos finais de semana. Algumas das experiências concretizadas durante a realização deste curso foram objeto de análise, por uma questão de espaço neste texto vamos remeter para outros trabalhos onde exploramos aspectos da proposta sob

\footnotetext{
${ }^{1}$ Educação Básica corresponde dos primeiros anos da Educação Infantil ao Ensino Médio, ou conforme é denominado em alguns países, este último nível, de "Secundária".
} 
diferentes enfoques (cf. Silva e Fontebasso, 2006, 2007a, 2007b). Uma das características da proposta global deste curso propunha a vivência de docência compartilhada ${ }^{2}$ como fator de enriquecimento pedagógico e amplitude de abordagens, exercitando na prática a ideia do diálogo permanente entre professor-professor e professor-aluno.

Neste trabalho nos propomos, a partir do uso do recurso da memória, a reconstruir elementos desta experiência à luz do tempo presente, atualizando a experiência, revendo posturas, aprendendo com o que se fez no processo inicial de formação de educadores. O lugar e o espaço em que se movimenta a construção desta tradução é a dinâmica relação vivenciada pelos autores/atores no ato da docência compartilhada. Destacamos também que viemos explorando o potencial da memória como um elemento fecundante para repensar e atualizar o que se faz em educação. Em trabalho anterior (Silva e Fontebasso, 2009), exercitamos este recurso, tomando como objeto de estudo o ato de ler e escrever. Nosso olhar se volta agora para a prática da docência universitária compartilhada em uma experiência singular de formação de professores.

Para tanto, apresentamos inicialmente os pressupostos teóricos que amparam nossa reflexão no que se refere à compreensão de memória. Seguido pela discussão sobre tradução, finalmente exploramos elementos da experiência de docência compartilhada a partir de alguns aspectos que a memória permitiu reatualizar.

\section{Sobre a memória}

Muito se vive de experiências ao longo de uma existência. Desse vivido, a grande maioria não se transforma em narrativa, seja oral ou escrita, menos ainda se essa escrita deve receber um tratamento que exige maior cuidado. Da memória da experiência feita na formação de professores, através de docência compartilhada, propomos localizar algumas ideias que nos inspiram a reconstruir, pela textualidade, certamente não o todo, mas partes da experiência que ganharam significado em nossas práticas atuais de educadores e formadores. Tais significados contribuem para a constituição de sujeitos-pessoas-profissionais.

Ainda que a memória pareça ser algo exclusivamente individual, ela deve ser também compreendida como um fenômeno social e coletivo (Pollak, 1992). Dessa forma, podemos sublinhar que a memória é tanto individual quanto coletiva, de uma forma geral. Daí podermos atribuir à memória características semelhantes a ambas as instâncias, tais como: a mutabilidade, a inconstância, a flexibilidade e a fluidez. Michael Pollak chama a atenção para o fato de que, mesmo sendo mutante, a memória apresenta "marcos" ou "pontos" que são relativamente fixos ou "imutáveis". Seguimos as indagações de Pollack: "Quais são, portanto, os elementos constitutivos da memória, individual ou coletiva? Em primeiro lugar, são os acontecimentos vividos pessoalmente. Em segundo lugar, são os acontecimentos que eu chamaria de 'vividos por tabela', ou seja, acontecimentos vividos pelo grupo ou pela coletividade à qual a pessoa se sente pertencer” (1992, p. 202). Falando de formação de educadores e de uma experiência singular vivida, cabe-nos, nesta perspectiva, considerar que o reconstruir dessa experiência pelo recurso da memória será atravessado tanto pelos acontecimentos vividos pelos autores, como por aqueles que significam e dão sentido ao pertencimento de grupo, neste caso a categoria profissional à qual nos vinculamos: os professores. É sabido que existe um discurso "comum" que identifica e vincula os profissionais da educação. Tal discurso também é aludido como um certo "pedagogês", que aqui lembramos no sentido positivo

2 A ideia da docência compartilhada situa-se na perspectiva do trabalho em parceria, envolvendo o planejamento conjunto das atividades docentes a serem realizadas com o grupo de estudantes. Implica, entre outros aspectos, a exigência de uma mudança de postura por parte do formador, que ao dividir o espaço da docência também coloca-se no lugar de quem aprende. 
do termo, distanciando-nos da perspectiva pejorativa e estereotipada que em alguns contextos é utilizado para referir-se ao que fazem os profissionais do campo da educação. Pollack esclarece que: São acontecimentos dos quais a pessoa nem sempre participou, mas que, no imaginário, tomaram tamanho relevo que, no fim das contas, é quase impossível que ela consiga saber se participou ou não. Se formos mais longe, a esses acontecimentos vividos por tabela vêm se juntar todos os eventos que não se situam dentro do espaço-tempo de uma pessoa ou de um grupo. É perfeitamente possível que, por meio da socialização política, ou da socialização histórica, ocorra um fenômeno de projeção ou de identificação com determinado passado, tão forte que podemos falar numa memória quase que herdada (Pollack, 1992, p. 202)

Neste aspecto talvez consigamos, através de um controle consciente, estabelecer distinções entre o vivido e o experimentado diretamente e aquilo originário de uma memória herdada do campo da educação, que, de alguma maneira, vão sendo acionadas, somando-se às experiências de fato vividas pelos autores. Para além do acontecimento, outro elemento é agregado por Pollack como constitutivo da memória, a ideia de personagem: “(...) falar de personagens realmente encontradas no decorrer da vida, de personagens frequentadas por tabela, indiretamente, mas que, por assim dizer, se transformaram quase que em conhecidas, e ainda de personagens que não pertenceram necessariamente ao espaço-tempo da pessoa" (Pollack, 1992, p.202). Um terceiro elemento é apontado por Pollack na constituição da memória, os lugares:

Existem lugares da memória, lugares particularmente ligados a uma lembrança, que pode ser uma lembrança pessoal, mas também pode não ter apoio no tempo cronológico. Pode ser, por exemplo, um lugar de férias na infância, que permaneceu muito forte na memória da pessoa, muito marcante, independentemente da data real em que a vivência se deu. Na memória mais pública, nos aspectos mais públicos da pessoa, pode haver lugares de apoio da memória, que são os lugares de comemoração (1992, p. 202-203).

Para além dos elementos constitutivos da memória aportados por Pollack, nos é significativo acentuar o fato de que a memória é seletiva. Evidencia-se tal aspecto, considerando que nos propomos a reconstruir uma experiência traduzida pela textualidade e, com isso, naturalmente selecionar episódios que ganharão visibilidade, outros nesta construção serão silenciados. Barreira (2007, p. 104) assim se refere a este aspecto: "A própria memória é seletiva na designação do que é "necessário lembrar" ou "precisa ser esquecido" no sentido de instituir credibilidade". Portanto, ao tornar conhecível na tradução que se faz, têm-se consciência dessas dimensões que compõem, conformando e informando uma leitura da experiência feita. Acentua-se que sempre será uma forma de ler a experiência, e não a única. "As memórias (e é importante pensá-las no plural) afirmam grupos, identidades e denegam outros pela omissão” (Barreira, 2007, p. 104). Em síntese, podemos dizer com Viana (2005):

La memoria es lo que nos pasa e incluso lo que no nos pasa. Determinará incluso en gran medida lo que nos vaya a ocurrir. Los episodios de nuestra vida son la apariencia visible, las fachadas de las casas que vemos al pasar por una calle, pero la memoria son los entramados que las sostienen, su estructura, el revés de la trama; un conocimiento que, en ocasiones, parece invisible, pero permanece allí en la sombra (p. 215-216).

Para que não permaneça nas sombras aquilo que vem sustentando as ações educativas, nos propomos, ao utilizar o texto como recurso, a abrir as portas das "casas" que habitamos, revelando parte do que as sustentam. "La escritura sería la huella de la pisada en la nieve, el vestigio de la palabra - siempre haciéndose y cambiando de lugar - y la memoria la forma de ésta, la planta que la 
hizo posible. La misma forma que quedará tras nuestros pasos en el níveo suelo que aún está por venir" (Viana, 2005, p. 215-216) ${ }^{3}$.

Outro esclarecimento se faz necessário e diz respeito ao tempo. Para isso, nos reportamos a Reinhart Koselleck (1923-2006), que, ao propor as categorias Espaço da experiência e horizontes de expectativas como forma de refletir sobre o tempo histórico, contribui para a explicitação de nossa reflexão. Para o autor, estas categorias são as condições de possibilidades histórias concretas e, portanto, são igualmente categorias de uma epistemologia própria do conhecimento que fundamenta a história como campo de conhecimento (Mudrovcic, 2005).

A categoria espaço da experiência é compreendida por Koselleck como "passado atual, aquele no qual acontecimentos foram incorporados e podem ser lembrados" (2006, p. 309). Neste sentido, é importante esta primeira categoria para que repensemos o processo da experiência vivida, ou seja, como algo que é reatualizado no presente, unindo tanto a racionalização quanto aspectos do comportamento da experiência feita, assim a experiência do passado vai sendo revitalizada no tempo presente.

Já a categoria horizontes de expectativas, para Koselleck, "se realiza no hoje, é futuro presente, voltado para o ainda-não, para o não experimentado, para o que ainda não pode ser previsto" (2006, p. 310). Mais do que se oporem, estas duas ideias demarcam a tensão própria do tempo histórico. $\mathrm{Na}$ interpretação de Mudrovcic (2005), estas duas categorias são “anticipaciones vinculadas a acontecimientos pasados, transmitidos y conservados. Inversamente, las expectativas no cumplidas, los acontecimientos que no responden a las anticipaciones se transforman en nuevas experiencias" (p.101). ${ }^{4}$

Situamos nesta direção a reflexão que apresentamos. Ao tomarmos a experiência realizada de docência compartilhada como espaço da experiência, mobilizada, pelo horizonte de expectativas nutrido pelos docentes. Observamos, igualmente, que entre as expectativas que potencializaram a concretização da experiência, no ato de viver a experiência, tensões foram acionadas, complexificando o processo da experiência no presente do vivido e que, tomadas neste momento como um passado-presente, ganham novos aportes pela sistematização e reflexão sobre este passado-presente.

\section{Sobre a tradução da memória em discurso: o processo da narração}

É importante deter-nos sobre o processo de tradução do que a memória reteve das experiências feitas. Que aspectos considerar quando se utiliza da memória como recurso acionador de experiências retidas e traduzidas pela narração em forma de textualidade? Que sensibilidades devem ser valorizadas e reconhecidas neste processo? Como constituir-se autor no processo narrativo da própria experiência feita? E, por último, como conjugar, selecionar, filtrar "retalhos" da experiência, retidos pela memória, partindo de dois pólos que recordam, ou seja, partindo de dois sujeitos que experimentaram juntos? Entretanto, conforme o já exposto no item anterior, as retenções memoriais são individuais e também coletivas.

Sem a pretensão de responder a essas perguntas, vamos nos guiar por elas para construir nossa reflexão. Ou como diz a pesquisadora argentina Beatriz Sarlo (2007, p.12): "Fala-se do passado sem suspender o presente, e muitas vezes, implicando também o futuro. Lembra-se, narra-

\footnotetext{
3 “A escrita seria a marca da pisada na neve, o vestígio da palavra - sempre se fazendo e mudando de lugar e a memória a forma desta, o projeto que a tornou possível. A mesma forma que ficará de nossos passos no solo plano que ainda está por vir" (VIANA, 2005, p. 215-216).

4 "antecipações vinculadas a acontecimentos passados, transmitidos e conservados. Inversamente, as expectativas não cumpridas, os acontecimentos que não respondem às antecipações se transformam em novas experiências" (p.101).
} 
se ou se remete ao passado por um tipo de relato, de personagens, de relação entre suas ações voluntárias e involuntárias, abertas e secretas (...)".

Ao narrar uma experiência, criamos uma espécie de temporalidade presente, atualizando o passado e, no nosso caso, procurando retirar desse passado presentificado aprendizagens que contribuíram para a nossa ação docente, principalmente no que se refere à atuação nos processos de formação inicial de professores, e que ganham evidências também nas práticas de formação continuada. Assim, garantindo sempre algo novo que se instaura, que se apresenta, que ganha materialidade discursiva e que, para o próprio narrador, não era claro. Sarlo (2007) denomina esse movimento como irrepetivel, ou aquilo que a cada momento é repetido acaba se atualizando e nunca se apresentando da mesma forma, do mesmo modo que foi produzido na primeira narração. "A narração inscreve a experiência numa temporalidade que não é a de seu acontecer (ameaçados desde seu próprio começo pela passagem do tempo e pelo irrepetível), mas a de sua lembrança” (p. 25).

Sarlo lembra uma das possíveis funções da memória no ato de narrar, uma vez que, ao narrar uma experiência vivida, o narrador ampara-se nos detalhes para que a narração ganhe uma veracidade indiscutível enquanto verdade, e uma das formas é enriquecer a narrativa de detalhes, por mais insignificantes que sejam: "O discurso da memória, transformado em testemunho, tem a ambição da autodefesa; quer persuadir o interlocutor presente e assegurar-se uma posição no futuro; justamente por isso também é atribuído a ele um efeito reparador da subjetividade” (2007, p. 51).

Alertados por Sarlo, no que diz respeito à "ambição de autodefesa”, e talvez pela busca da reparação daquilo que podia ter sido feito melhor e mais qualificado, ou como diz a autora com um "efeito reparador", ao rememorar através da narração tornada visível pela textualidade, retomamos a experiência feita de forma mais consciente e objetiva. Aliado a isso, a presença do outro sujeitoautor assume papel importante neste processo de "controle e vigilância" dos retalhos que vão sendo costurados, nesta rede de informações que demarcou um acontecimento de longo prazo, dado na interatividade com um coletivo de alunos em processo de formação. "É inevitável a marca do presente no ato de narrar o passado, justamente porque, no discurso, o presente tem uma hegemonia reconhecida como inevitável e os tempos verbais do passado não ficam livres de uma experiência fenomenológica do tempo presente da enunciação” (Sarlo, 2007, p. 49).

Ganha sentido a ideia da constituição do sujeito que narra com marcas do presente uma experiência do passado, tendo um objetivo (que aponta para o futuro). Manuel Cruz assinala com propriedade esse sentido a partir de duas frentes: “(...) hacia el pasado y hacia el futuro. De aquel lado, el sujeto es alguien que compone relatos de los acontecimientos sucedidos, elabora historias, cuenta y se cuenta lo que ocurrió. De este otro, el sujeto es alguien capaz de fijarse objetivos, promover iniciativas, proponerse fines" (2000, p. 26) ${ }^{5}$.

Corrobora Sarlo (2007): "Em suma, não se pode representar tudo o que a experiência foi para o sujeito, pois se trata de uma "matéria prima" em que o sujeito-testemunha é menos importante que os efeitos morais de seu discurso" (p.36). Neste sentido, a ideia de tradução da memória em textualidade persegue uma vontade de tornar visível o invisível, de deixar, através da "porta aberta da casa", que as estruturas que a sustentam sejam perceptíveis ao outro, neste caso, o leitor. Procurar-se-á, na medida do possível, que os processos de negociação entre os retalhos lembrados ganhem uma unidade, de tal forma que possam ser integrados dentro da estrutura do saber formulado pela experiência, e que a memória permite registrar. No dizer de Cruz (2000), a proposta de narração constitui uma vontade de síntese, unificando, a partir de uma elaboração particular, uma experiência feita: "La propuesta de la narración es una propuesta compleja, como la

5 “(...) rumo ao passado e rumo ao futuro. De um lado, o sujeito é alguém que compõe relatos dos acontecimentos sucedidos, elabora historias, conta e se conta o que aconteceu. De outro, o sujeito é alguém capaz de se fixar objetivos, promover ações, propor-se fins" (2000, p. 26). 
realidad misma. La narración podría ser el espacio de la reconciliación entre los diversos saberes y discursos acerca de lo humano" ( p. 38)

\section{Elementos da experiência de docência compartilhada}

A experiência de docência compartilhada, que se constitui em objeto de análise neste trabalho, ocorreu durante um período de dois anos (2003-2004), distribuídos em quatro semestres acadêmicos. A turma foi composta por alunos do curso de pedagogia, turma singular, estruturada a partir de uma parceria entre universidade e Secretaria Municipal de Porto Alegre. Objetivava formar educadores atuantes em espaços populares localizados, em grande parte, na periferia da cidade. Uma das características dos alunos era marcada pela prática docente já em andamento, portanto uma formação em serviço, com o fim de qualificar educadores atuantes em meios marginalizados e empobrecidos. Cabe uma observação quanto à dimensão de idealismo e, inclusive, à noção revisitada de "militância" e engajamento político, tanto por parte dos alunos quanto por parte dos formadores que assumiram a proposta de formação. O total de alunos que compunha a turma foi de 150 .

Os formadores trabalharam com apoio de monitores, estudantes de pedagogia de outras universidades que se encontravam em semestres avançados do curso, geralmente, cursando $5^{\circ}$ e $6^{\circ}$ semestres. Os monitores tinham a função, dentre outras, de contribuir com o processo pedagógico, coordenar grupos de discussão, assessorar os formadores responsáveis pelo componente curricular, realizar registros etc.

O espaço para a realização das aulas oscilou entre o auditório de uma escola pública estadual, localizada na parte central da cidade de Porto Alegre, e um salão "improvisado" das próprias instalações da administração da universidade que se encontrava em processo de implantação. Esta breve descrição serve como panorama do contexto em que ocorreu a experiência.

\section{Das narrações em curso}

Na experiência com “os 150” buscávamos ocupar, professor e aluno, o lugar de narrador enquanto exercíamos um trabalho que privilegiava a retomada do que era produzido como tarefa acadêmica, dando-lhe o sentido de que cada sujeito era capaz de retornar ao produzido após o olhar do professor, com o desafio de burilar, melhorar, tornar mais rigoroso o que havia sido feito num primeiro momento. Apostávamos não apenas na possibilidade de produções rigorosas do ponto de vista científico, mas no desenvolvimento de uma capacidade de reflexão sobre o feito e, por isso mesmo, sobre a capacidade individual de superar-se. O que nos preocupava, talvez mais do que as "folhas escritas" (sem descurar da necessidade de um resultado), era a construção de um lugar que acreditava na capacidade de superação de cada sujeito. No movimento individual de ultrapassar-se, apostávamos também na construção coletiva de outro modo de ser e de ver-se, enquanto sujeito e enquanto grupo. Por que aquele grupo tinha entrado na universidade achando-se "menos", tanto no sentido de suas capacidades, quanto do seu lugar social de onde provinham em sua maioria. Ou, talvez mais, por esse originário lugar social. Isso, para nós, era reconstruir e reconciliar os saberes e os discursos do humano. No entanto, essa clareza só foi possível mais tarde, em tempos de reflexão posterior aos acontecimentos, no ato de rememoração. Naquele tempo, o que fazíamos era movido por forças advindas de nossas crenças no ser humano e do comprometimento com o ato de educar. Era a urgência do viver o cotidiano docente que nos ditava as ações. Mas o ato de rememoração teve suas raízes nas narrativas que eram construídas durante a experiência, tanto por nós, professores, quanto pelos alunos.

6 "A proposta da narração é uma proposta complexa, como a realidade mesma. A narração poderia ser o espaço da reconciliação entre os diversos saberes e os discursos acerca do humano” ( p. 38). 
As narrativas estavam presentes nas reflexões sobre o que fazíamos nos posicionamentos assumidos enquanto negociações com os alunos sobre tarefas a serem cumpridas e nem sempre bem aceitas, mas consideradas por nós como fundamentais. Era do próprio espaço-tempo do diálogo, nem sempre cordiais, que emergiam as narrativas dos estudantes que negociavam o tempo todo a sua própria condição de vida com um projeto de formação em andamento. Negociação que implicava a permanência no próprio curso, pois ao se realizar aos sábados o curso obrigava a realização das refeições e lanches durante o dia, que para uma maioria era oneroso, aliado à exigência do próprio deslocamento, outro investimento, assim pode se dizer que eram seres que lutavam para ensinar e aprender, o que, neste espaço, acabava sendo exercido por ambos (professor e aluno).

Tudo isso caracterizava um tempo, em que a dupla de professores se encontrava com os alunos. Havia o espaço do olhar-se e da conversa um diante do outro, num esforço de construir em conjunto, não só conhecimentos constitutivos do currículo do curso, mas da própria subjetividade, enquanto necessidade de seres comprometidos com o outro.

\section{Do estranhamento e da insegurança da exposição frente ao outro colega}

Ainda que os dois docentes não fossem estranhos, pois já haviam trabalhado juntos em outra instituição, o fato de compartilhar um componente curricular e dividir o mesmo espaço, e por que não dizer, as atenções, era uma situação nova em que se deveria aprender a conviver. Os preparativos, o processo de planejamento das aulas, os encontros pautados pela preocupação em organizar um plano de atividades, na medida em que se intensificaram pelas exigências cotidianas do componente curricular, também foram permitindo a criação de vínculos e de laços de solidariedade.

As primeiras "exposições" dos docentes no espaço da sala de aula foram demarcadas pela necessidade de encontrar um lugar próprio, pois o que se apresentava era uma comunicação que se dava, ao mesmo tempo, com um colega-professor e com os alunos. Tal situação impelia constantemente, nas primeiras aulas, a buscar um tipo de linguagem que "satisfizesse" tanto o colega ouvinte-parceiro quanto os alunos, que, por sua vez, acabava criando uma instabilidade emocional. Internamente, se apresentava a necessidade de controlar, nas primeiras interações, o discurso produzido durante as atividades em classe, ainda que isso não significasse uma perda de controle sobre a produção discursiva em ato. Nessa dinâmica, identidades profissionais foram se forjando no espaço social configurado pela prática da docência. No dizer de Cruz (2000), ao entrarmos em contato com o discurso do outro, constitui-se um lugar de encontro intersubjetivo que permite materializar a experiência, sistematizando-a: “(...) en el lugar del encuentro intersubjetivo, sirve al designio de homogeneizar la experiencia, de seleccionar, de entre la pluralidad de intensidades que cada individuo percibe, las relevantes, las constituyentes del objeto" (p. 30) ${ }^{7}$.

As inseguranças iniciais foram deslocando-se e constituindo-se em pontos de referência, abrindo espaço para a constituição de um trabalho em equipe onde a escuta e a busca por compreender o sentido do discurso do outro assumem preponderância. Esse movimento, sem que nos déssemos conta, foi preenchendo o vazio deixado pela insegurança, liberando a construção de uma fala mais livre, menos controlada e mais espontânea, ou seja, a constituição de um espaço marcado, daí em diante, pela parceria e colaboração.

A aposta e a crença em um projeto de formação diferenciado do que a grande maioria das instituições oferece constituiu-se como um dos primeiros aspectos que possibilitou a criação de vínculo e do estabelecimento da parceria. O tempo, o contexto, as motivações, e mesmo as histórias pessoais de cada um dos docentes contribuíram para o sucesso de uma proposta que apostou na

7 “(...) no lugar do encontro intersubjetivo, serve ao desígnio de homogeneizar a experiência, de selecionar, dentre a pluralidade de intensidades que cada individuo percebe, as relevantes, as constituintes do objeto" (p. $30)$. 
participação e no compromisso ativo dos docentes e estudantes. Entretanto, não é comum encontrar estas dimensões presentes nos processos formativos.

\section{Dos aprendizados realizados: conclusão}

Objetivou-se neste trabalho aportar elementos para se pensar sobre uma experiência na formação inicial de professores a partir da prática da docência compartilhada. Procurou-se apoio para a reflexão na discussão sobre o papel da memória e os processos que envolvem a produção da narração. Apresentamos, em formato de síntese, alguns dos aprendizados efetivados durante o próprio processo de construção da narração pela textualidade.

Justamente o primeiro aspecto a ressaltar refere-se ao potencial da memória problematizada e compreendida como forma de atualizar o passado no presente, tornando explicito, quase que num processo reparador de lembranças, retalhos ou fragmentos de uma experiência feita como forma de ativar a capacidade de aprender. Nesse sentido, o campo da formação de professores carece de investimento no campo da pesquisa, pois se observa um instrumental teórico potente que permite maximizar e, mesmo, estimular a capacidade reflexiva daquilo que se faz no cotidiano de tantos educadores. Uma possibilidade carregada de alternativas que evocam o lugar do educador como protagonista do processo de pensar a educação em sua dimensão mais ampla, ou seja, articulando espaços de reflexão e de repensar a própria ação educativa. Um elemento que pode e deve ser incorporado em práticas de formação, inclusive na formação continuada, onde historicamente se detecta as maiores lacunas de uma formação que tenha sentido para os educadores.

Por outro lado, reforça-se a crença no trabalho cooperativo das práticas docentes. Neste trabalho enfatizamos a prática docente do ensino superior voltado para a formação inicial de educadores. O trabalho de reconstrução da experiência, através das lembranças que a memória permitiu atualizar, aponta para esse potencial. De um lado, como etapa auto-formativa no próprio exercício da prática docente, desestabilizando a cultura da prática docente individualizada, preconizando a parceria como elemento construtivo de alternativas possíveis de serem vivenciadas. De outro lado, a dinâmica que se institui no processo de docência compartilhada possibilita aos alunos o acesso a diferentes abordagens e pontos de vista sobre uma mesma temática posta em discussão durante o quefaz̧er educativo cotidiano da sala de aula.

Finalmente, assume evidência o planejamento do trabalho realizado como pressuposto básico para o trabalho de parceria, distanciando-se de práticas individualizadas, ou, então, pela simples distribuição de tarefas ou responsabilidades. A dimensão da parceria defendida aqui toma como princípio o planejamento realizado em cooperação, com antecedência, demarcado pela abertura à escuta do outro no ato de fazer a docência. Assim, o diálogo aberto, franco e espontâneo, durante as atividades docentes, assume papel preponderante para o sucesso de experiências e projetos formativos que vislumbrem ações compartilhadas.

\section{Referências}

BARREIRA, Irlys. (2007) A eficácia simbólica da memória e seus limites. Revista Brasileira de Ciências Sociais, vol. $22 \mathrm{n}^{\mathrm{o}}$ 63. p. 93-105

CRUZ, Manuel. (2000) Tiempo de narratividad (el sujeto, entre la memoria y el proyecto). Anàlisi 25, 25. p. $23-40$

KOSELLECK, Reinhart. (2006) Futuro Passado. Contribuição à semântica dos tempos históricos (Tradução: Wilma Patrícia Maas; Carlos Almeida Pereira). Rio de Janeiro: Contraponto/PUCRJ. 
MUDROVCIC, María Inés. (2005) Historia, narración y memoria. Los debates actuales en filosofía de la historia. Madrid: Akal.

POLLAK, Michael. (1992) Memória e identidade social (Tradução Monique Augras). Estudos Históricos, Rio de Janeiro, vol. 5, n. 10, p. 200-212.

SARLO, Beatriz. (2007) Tempo passado. Cultura da memória e guinada subjetiva. Tradução: Rosa Freire d'Aguiar. São Paulo: Companhia das Letras; Belo Horizonte: Editora UFMG.

SILVA, Gilberto Ferreira da; FONTEBASSO, Maria Rosa. O estatuto da leitura e escrita na formação de professores: reminiscências memoriais da experiência docente. Revista de Innovación Educativa. Universidade de Santiago de Compostela, v. 19, p. 193-205, 2009.

SILVA, Gilberto Ferreira da; FONTEBASSO, Maria Rosa. Formação de professores: o curso "150" da UERGS, driblando impasses, enfrentando limites, criando alternativas. In: NOGUEIRA, S. V, et. al.(orgs.). Saberes e práticas de ensino e pesquisa. Canoas, La Salle. 2006. p. 71-85

SILVA, Gilberto Ferreira da; FONTEBASSO, Maria Rosa. Pesquisa na formação de professores: o desafio docente de articular a prática com a produção do conhecimento. In: CASTRO E SILVA, D. M; FISS, Dóris M. L, FONTEBASSO, M. R. (orgs.). Formação de professores: histórias, memórias e educação popular. Porto Alegre, Martins Livreiro. 2007a. p. 81-94.

SILVA, Gilberto Ferreira da; FONTEBASSO, Maria Rosa. Processo de avaliação: desafio frente às diferenças. In: CASTRO E SILVA, D. M; FISS, D. M. L, FONTEBASSO, M. R. (orgs.). Formação de professores: histórias, memórias e educação popular. Porto Alegre, Martins Livreiro. 2007b. p. 103-115.

VIANA, Luis Díaz G.. Los caminos de la memoria: oralidad y textualidad en la construcción social del tiempo. Acta Poetica 26 (1-2), 2005. p. 181-217

\section{Sobre os Autores}

Gilberto Ferreira da Silva realizou Pós-doutorado na Universidade de Barcelona, é Doutor em Educação pela Universidade Federal do Rio Grande do Sul, com tese defendida sobre educação intercultural no espaço da escola pública. Atualmente é Professor Adjunto do Programa de Mestrado em Educação e do Curso de Pedagogia do Unilasalle-Canoas-RS. Desenvolve pesquisas no campo da formação de professores, diversidade cultural, relações étnicorraciais e política públicas. Consultor de periódicos nacionais e internacionais. Pesquisador do CNPq. Email: gilberto.ferreira65@gmail.com

Maria Rosa Fontebasso é Doutora em Educação pela Universidade Federal do Rio Grande do Sul, com tese sobre Educação de Jovens e Adultos. Atualmente é aposentada. Email:

mirosa@terra.com.br

\section{Sobre as Editoras Convidadas}

\section{Carla Beatriz Meinerz}

Universidade Federal do Rio Grande do Sul

Doutora em Educação pela Universidade Federal do Rio Grande do Sul. Professora Adjunta no Departamento de Ensino e Currículo da Faculdade de Educação.

carlameinerz@gmail.com 


\section{Dóris Maria Luzzardi Fiss}

Universidade Federal do Rio Grande do Sul

Doutora em Educação pela Universidade Federal do Rio Grande do Sul. Professora Adjunta no Departamento de Ensino e Currículo da Faculdade de Educação.

fiss.doris@gmail.com

\section{Sônia Mara Moreira Ogiba}

Universidade Federal do Rio Grande do Sul

Mestre em Educação pela Universidade Federal do Rio Grande do Sul. Professora do

Departamento de Ensino e Currículo da Faculdade de Educação. Membro da Associação

Psicanalítica de Porto Alegre (APPOA) e Instituto APPOA - Clínica, Pesquisa e Intervenção

Social.

ogb@cpovo.net

\section{arquivos analíticos de políticas educativas}

\section{Revista acadêmica avaliada por pares}

Volume 21 Número 26 de março 2013

ISSN 1068-2341

Ca)
SURTERIGHIS RESERVED O Copyright e retido pelo/a o autor/a (ou primeiro co-autor) que outorga o
direito da primeira publicação à revista Arquivos Analíticos de Políticas Educativas. Más
informação da licença de Creative Commons encontram-se em
http://creativecommons.org/licenses/by-nc-nd/2.5. Qualquer outro uso deve ser aprovado em
conjunto pelo/s autor/es e por AAPE/EPAA. AAPE/EPAA é publicada por Mary Lou Fulton
Institute Teachers College da Arizona State University. Os textos publicados em AAPE são indexados por
CIRC (Clasificación Integrada de Revistas Científicas, Espanha) DIALNET (Espanha), Directory of
Open Access Journals, Education Full Text (H.W. Wilson), EBSCO Education Research Complete,
, ERIC, QUALIS A2 (Brasil), SCImago Journal Rank; SCOPUS, SOCOLAR (China). Contribua
com comentários e sugestões a http://epaa.info/wordpress/




\section{arquivos analíticos de políticas educativas conselho editorial}

Editor: Gustavo E. Fischman (Arizona State University) Editores Associados: Rosa Maria Bueno Fisher e Luis A. Gandin

(Universidade Federal do Rio Grande do Sul)

Dalila Andrade de Oliveira Universidade Federal de Minas Gerais, Brasil

Paulo Carrano Universidade Federal Fluminense, Brasil

Alicia Maria Catalano de Bonamino Pontificia Universidade Católica-Rio, Brasil

Fabiana de Amorim Marcello Universidade Luterana do Brasil, Canoas, Brasil

Alexandre Fernandez Vaz Universidade Federal de Santa Catarina, Brasil

Gaudêncio Frigotto Universidade do Estado do Rio de Janeiro, Brasil

Alfredo M Gomes Universidade Federal de Pernambuco, Brasil

Petronilha Beatriz Gonçalves e Silva Universidade Federal de São Carlos, Brasil

Nadja Herman Pontificia Universidade Católica Rio Grande do Sul, Brasil

José Machado Pais Instituto de Ciências Sociais da Universidade de Lisboa, Portugal

Wenceslao Machado de Oliveira Jr. Universidade Estadual de Campinas, Brasil
Jefferson Mainardes Universidade Estadual de Ponta Grossa, Brasil

Luciano Mendes de Faria Filho Universidade Federal de Minas Gerais, Brasil

Lia Raquel Moreira Oliveira Universidade do Minho, Portugal

Belmira Oliveira Bueno Universidade de São Paulo, Brasil

António Teodoro Universidade Lusófona, Portugal

Pia L. Wong California State University Sacramento, U.S.A

Sandra Regina Sales Universidade Federal Rural do Rio de Janeiro, Brasil

Elba Siqueira Sá Barreto_Fundação Carlos Chagas, Brasil

Manuela Terrasêca Universidade do Porto, Portugal

Robert Verhine Universidade Federal da Bahia, Brasil

Antônio A. S. Zuin Universidade Federal de São Carlos, Brasil 


\section{archivos analíticos de políticas educativas consejo editorial}

Editor: Gustavo E. Fischman (Arizona State University)

Editores. Asociados Alejandro Canales (UNAM) y Jesús Romero Morante (Universidad de Cantabria)

Armando Alcántara Santuario Instituto de Investigaciones sobre la Universidad y la Educación, UNAM México

Claudio Almonacid Universidad Metropolitana de Ciencias de la Educación, Chile

Pilar Arnaiz Sánchez Universidad de Murcia, España

Xavier Besalú Costa Universitat de Girona, España

Jose Joaquin Brunner Universidad Diego Portales, Chile

Damián Canales Sánchez Instituto Nacional para la Evaluación de la Educación, México

María Caridad García Universidad Católica del Norte, Chile

Raimundo Cuesta Fernández IES Fray Luis de León, España

Marco Antonio Delgado Fuentes Universidad Iberoamericana, México

Inés Dussel FLACSO, Argentina

Rafael Feito Alonso Universidad Complutense de Madrid, España

Pedro Flores Crespo Universidad Iberoamericana, México

Verónica García Martínez Universidad Juárez Autónoma de Tabasco, México

Francisco F. García Pérez Universidad de Sevilla, España

Edna Luna Serrano Universidad Autónoma de Baja California, México

Alma Maldonado Departamento de Investigaciones Educativas, Centro de Investigación y de Estudios Avanzados, México

Alejandro Márquez Jiménez Instituto de Investigaciones sobre la Universidad y la Educación, UNAM México

José Felipe Martínez Fernández University of California Los Angeles, USA
Fanni Muñoz Pontificia Universidad Católica de Perú

Imanol Ordorika Instituto de Investigaciones Economicas - UNAM, México

Maria Cristina Parra Sandoval Universidad de Zulia, Venezuela

Miguel A. Pereyra Universidad de Granada, España

Monica Pini Universidad Nacional de San Martín, Argentina

Paula Razquin UNESCO, Francia

Ignacio Rivas Flores Universidad de Málaga, España

Daniel Schugurensky Universidad de TorontoOntario Institute of Studies in Education, Canadá

Orlando Pulido Chaves Universidad Pedagógica Nacional, Colombia

José Gregorio Rodríguez Universidad Nacional de Colombia

Miriam Rodríguez Vargas Universidad Autónoma de Tamaulipas, México

Mario Rueda Beltrán Instituto de Investigaciones sobre la Universidad y la Educación, UNAM México

José Luis San Fabián Maroto Universidad de Oviedo, España

Yengny Marisol Silva Laya Universidad Iberoamericana, México

Aida Terrón Bañuelos Universidad de Oviedo, España

Jurjo Torres Santomé Universidad de la Coruña, España

Antoni Verger Planells University of Amsterdam, Holanda

Mario Yapu Universidad Para la Investigación Estratégica, Bolivia 


\section{education policy analysis archives editorial board \\ Editor Gustavo E. Fischman (Arizona State University) Associate Editors: David R. Garcia \& Jeanne M. Powers (Arizona State University)}

Jessica Allen University of Colorado, Boulder

Gary Anderson New York University

Michael W. Apple University of Wisconsin, Madison

Angela Arzubiaga Arizona State University

David C. Berliner Arizona State University

Robert Bickel Marshall University

Henry Braun Boston College

Eric Camburn University of Wisconsin, Madison

Wendy C. Chi* University of Colorado, Boulder

Casey Cobb University of Connecticut

Arnold Danzig Arizona State University

Antonia Darder University of Illinois, UrbanaChampaign

Linda Darling-Hammond Stanford University

Chad d'Entremont Strategies for Children

John Diamond Harvard University

Tara Donahue Learning Point Associates

Sherman Dorn University of South Florida

Christopher Joseph Frey Bowling Green State University

Melissa Lynn Freeman* Adams State College

Amy Garrett Dikkers University of Minnesota

Gene V Glass Arizona State University

Ronald Glass University of California, Santa Cruz

Harvey Goldstein Bristol University

Jacob P. K. Gross Indiana University

Eric M. Haas WestEd

Kimberly Joy Howard* University of Southern California

Aimee Howley Ohio University

Craig Howley Ohio University

Steve Klees University of Maryland

Jaekyung Lee SUNY Buffalo
Christopher Lubienski University of Illinois, Urbana-Champaign

Sarah Lubienski University of Illinois, UrbanaChampaign

Samuel R. Lucas University of California, Berkeley

Maria Martinez-Coslo University of Texas, Arlington

William Mathis University of Colorado, Boulder

Tristan McCowan Institute of Education, London

Heinrich Mintrop University of California, Berkeley

Michele S. Moses University of Colorado, Boulder

Julianne Moss University of Melbourne

Sharon Nichols University of Texas, San Antonio

Noga O'Connor University of Iowa

João Paraskveva University of Massachusetts, Dartmouth

Laurence Parker University of Illinois, UrbanaChampaign

Susan L. Robertson Bristol University

John Rogers University of California, Los Angeles

A. G. Rud Purdue University

Felicia C. Sanders The Pennsylvania State University

Janelle Scott University of California, Berkeley

Kimberly Scott Arizona State University

Dorothy Shipps Baruch College/CUNY

Maria Teresa Tatto Michigan State University

Larisa Warhol University of Connecticut

Cally Waite Social Science Research Council

John Weathers University of Colorado, Colorado Springs

Kevin Welner University of Colorado, Boulder

Ed Wiley University of Colorado, Boulder

Terrence G. Wiley Arizona State University

John Willinsky Stanford University

Kyo Yamashiro University of California, Los Angeles

* Members of the New Scholars Board 